\title{
Verificação de Descolamento Cerâmico de Fachada por Meio da Termografia Infravermelha
}

\author{
Verification of facade ceramic detachment by infrared thermography
}

\author{
Antonio Isnar Patriota Junior ${ }^{1}$ (i) orcid.org/0000-0002-4665-3002 \\ Pedro Igor Bezerra Batista2 (i) orcid.org/0000-0003-3912-111X \\ Yêda Vieira Póvoas 2 orcid.org/0000-0003-1907-415X \\ ${ }^{1}$ Escola Politécnica de Pernambuco, Universidade de Pernambuco, Recife, Brasil \\ 2 Programa de Pós-Graduação em Engenharia Civil, Escola Politécnica de Pernambuco, Recife, Brasil \\ E-mail do autor principal: Antonio Isnar Patriota Junior isnar.patriota@gmail.com
}

\section{Resumo}

O crescimento da indústria da construção civil e o maior e acesso a diferentes materiais por parte dos usuários e construtoras contribuíram para o aumento do uso de sistema de fachada em revestimento cerâmico em edificações. Com a maior utilização vieram também os problemas decorrentes de falhas de execução e materiais não conformes, elevando o número de manifestações patológicas. O objetivo é contribuir com a área de inspeção predial de fachadas com termografia infravermelha através de um estudo de caso. Utilizou-se a técnica da termografia infravermelha, caracterizada por ser um ensaio não destrutivo, ser de rápida análise e baixo custo, para verificar a fachada de uma edificação que apresenta indícios de fadiga dos materiais. Foram obtidas imagens térmicas identificando pontos com variações de temperatura, indicando possíveis manifestações patológicas. Após análise foram identificados novos pontos de desplacamento ocultos, imperceptíveis em análise visual. No âmbito da manutenção predial, a termografia infravermelha demostrou ser uma tecnologia de grande utilidade, permitindo analisar manifestações patológicas existentes ainda na fase embrionária, evitando assim custos agravados de manutenção.

Palavras-Chave: Termografia infravermelha, Manifestação patológica, Descolamento cerâmico, Fachada

\begin{abstract}
The growth of the construction industry and the larger and access to different materials by users and builders have contributed to the increased use of ceramic cladding façade system in buildings. With greater use came also the problems arising from failures of execution and non-conforming materials, increasing the number of pathological manifestations. The objective is to contribute to the building inspection area of infrared thermography façades through a case study. The technique of infrared thermography was used, characterized by being a non-destructive test, being of rapid analysis and low cost, to verify the facade of a building that shows signs of fatigue of the materials. Thermal images were obtained identifying points with temperature variations, indicating possible pathological manifestations. After analysis were identified new hidden slippage points, imperceptible in visual analysis. In the context of building maintenance, infrared thermography has proved to be a very useful technology, allowing to analyze pathological manifestations still in the embryonic phase, thus avoiding aggravated maintenance costs.
\end{abstract}

Key-words: Infrared thermography, pathological manifestations, ceramic tile detachment, building's facade. 
1.

\section{Introdução}

O revestimento cerâmico vem sendo usado desde a antiguidade para revestir pisos e paredes. A grande vantagem de sua utilização reside principalmente nas características de durabilidade, facilidade de limpeza, além do aspecto estético agradável.

Em matéria publicada pela revista Exame [1], o Brasil é o segundo maior produtor de revestimentos cerâmicos e também o segundo maior mercado consumidor do mundo, ficando atrás apenas da China. Porém, com o maior consumo e a maior acessibilidade de usuários e construtoras a este tipo de material, verifica-se uma crescente demanda de análise e correção de manifestações patológicas envolvendo este produto.

Bauer [2] declara que as falhas que ocorrem nos revestimentos podem ser causadas por deficiência de projeto; por desconhecimento das características dos materiais empregados e/ ou emprego de materiais inadequados; por erros de execução, seja por deficiência de mão de obra, desconhecimento ou não da observância de Normas Técnicas e por problemas de manutenção.

Matias; Póvoas [3], em pesquisa realizada na cidade de Recife, identificaram o descolamento do revestimento cerâmico como principal manifestação patológica encontrada em fachadas de edificações correspondendo a $37 \%$ dos casos (Figura 1).

Bauer [2] afirma que as causas mais comuns do descolamento cerâmico são a inexistência de juntas de movimentação, deficiências na execução do assentamento das peças e até a falta de rejuntamento.

A NBR 13755 [4] recomenda a execução de juntas horizontais de movimentação espaçadas no máximo a cada $3 \mathrm{~m}$ ou a cada pé-direito, na região de encunhamento da alvenaria; e a execução de juntas verticais de movimentação espaçadas no máximo a cada $6 \mathrm{~m}$. Não havendo o cumprimento dessas recomendações podem ocorrer manifestações patológicas.
Figura 1. Manifestações patológicas em fachadas

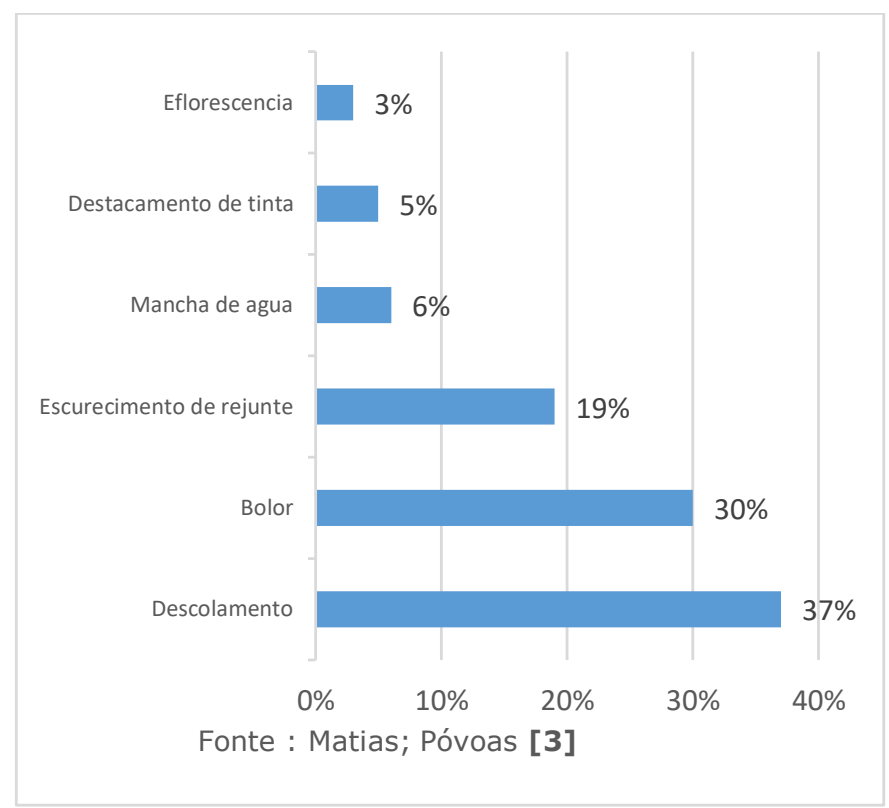

Este trabalho tem como objetivo contribuir com a área de inspeção predial de fachadas com termografia infravermelha através da análise desta técnica em um estudo de caso. Foi utilizada a técnica da termografia infravermelha para verificar a fachada de uma edificação que apresenta indícios de fadiga dos materiais.

\section{Termografia de infravermelho}

Mendonça [5] afirma que a termografia por infravermelhos (TI) consiste na captação de imagens de calor (termogramas), não visíveis pelo olho humano, através de uma câmara termográfica.

Através da análise do termograma é possível identificar de forma rápida e eficiente manifestações patológicas ocultas na edificação. A Figura 2 é um exemplo de termograma, identificando pontos frios no teto.

Segundo Cortizo et al (apud Giorleo et al.,2002) [6], a termografia é uma técnica nãodestrutiva, bidimensional, utilizada na medição do campo de temperatura da superfície de todos os tipos de materiais. 
Figura 2. Exemplo de termograma

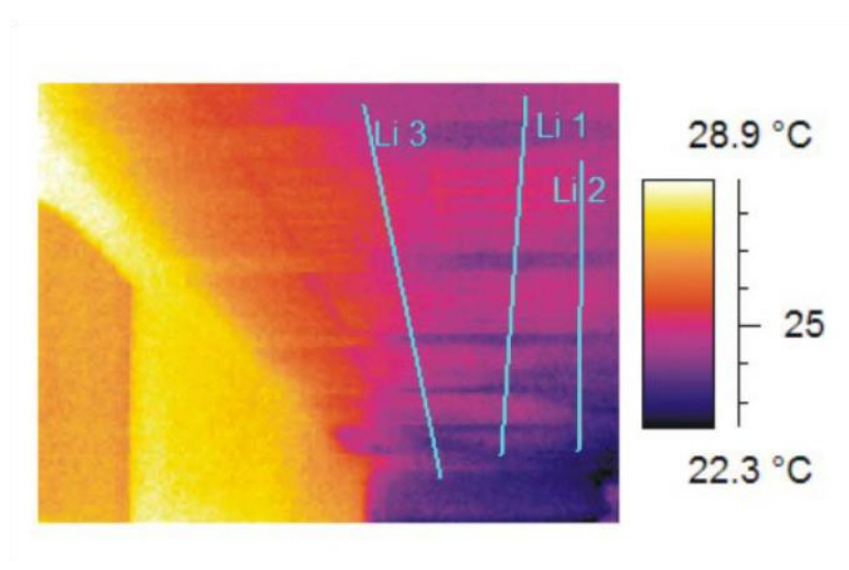

Fonte: Mendonça [5]

Por ser uma técnica não destrutiva, constitui poderosa ferramenta no âmbito da engenharia civil, em especial na área de manutenção predial. Seu resultado é instantâneo, possibilitando que o usuário possa avaliar o problema de forma mais precisa, melhorando o tipo de solução que deverá ser adotado.

A utilização da termografia infravermelha para análise de manifestações patológicas em fachadas é atestada por vários trabalhos científicos, a exemplo de Viégas [7] e Silva et al [8]. Ambos declaram que a técnica constitui ferramenta poderosa na predição de falhas, uma vez que é possível detectar manifestações patológicas em fachada de forma preventiva.

\section{Metodologia}

Para execução desta pesquisa foi seguida a seguinte metodologia:

- identificar a edificação a ser estudada;

- caracterizar o prédio, levantando dados sobre idade, tipo de uso, projeto de fachada, execução e manutenção;

- analisar visualmente a fachada;

- mapear a incidência solar na fachada visando obter o melhor resultado do ensaio termográfico;

- encontrar posição ideal para o ensaio de termografia;

- executar o ensaio de termografia infravermelha;

- analisar os resultados obtidos no ensaio de termografia.
Foi utilizada a câmera termográfica FLIR E-60 (Figura 3) para captar a radiação emitida pelos materiais da fachada, formando assim, a imagem térmica (termograma), ferramenta deste estudo.

Figura 3. Câmera termográfica FLIR E-60

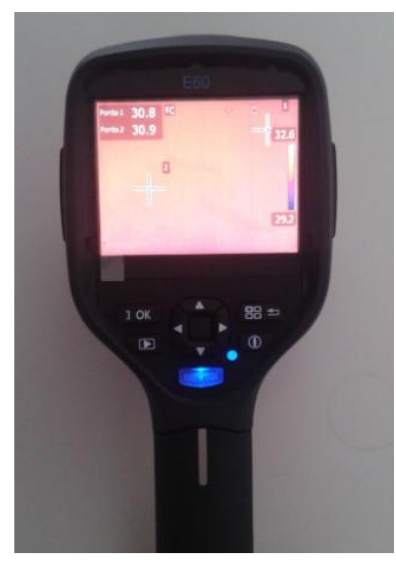

Resolução IR: 320x240 pixels

Peso: $0,825 \mathrm{~kg}$

Temperatura: $-20^{\circ} \mathrm{C}$ a

$650^{\circ} \mathrm{C}$

Precisão: $\pm 2{ }^{\circ} \mathrm{C}$

Bluetooth: sim

\subsection{Caracterização da edificação}

A Figura 4 apresenta a localização da edificação em estudo: o Centro de Educação Física e Desportos (CEFD) do Corpo de Bombeiros Militar de Pernambuco (CBMPE) situado à Avenida João de Barros, 399, bairro da Soledade, Recife- PE.

Figura 4. Localização do CEFD

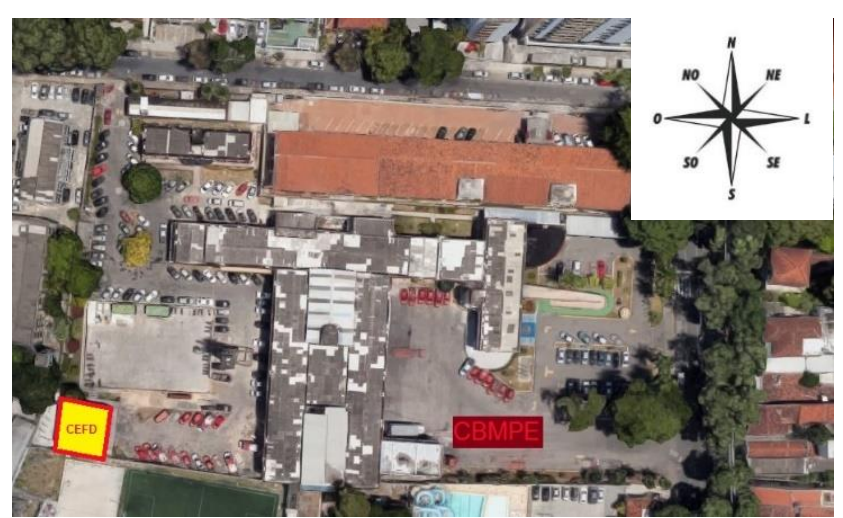

Fonte: https://maps.google.com.br

A edificação foi entregue no ano de 2006, sendo utilizada para o treinamento e condicionamento físico de militares.

É constituído por dois pavimentos, térreo e $1^{\circ}$ andar, sendo o pavimento térreo utilizado como academia e o primeiro pavimento utilizado como 
administração e salas de tatames. A estrutura é constituída de fundações em sapata, pilares, vigas e lajes de concreto armado, tendo blocos cerâmicos como elementos de vedação vertical.

O revestimento da fachada é constituído por placas cerâmicas $(10 \times 10 \mathrm{~cm})$ nas cores vermelha e branca, com área total de $280 \mathrm{~m}^{2}$. Não apresenta juntas de movimentação, apenas juntas de assentamento, com várias falhas.

O edifício não possui projeto executivo de fachada, e já passou por correções pontuais.

Para o presente estudo foi escolhida a fachada frontal da edificação, denominada fachada A (Figura 5), a fim de identificar patologias ocultas através da técnica da termologia infravermelha.

No período de análise, o sol irradiou a fachada A no período da manhã, sendo o período vespertino caracterizado como sombra.

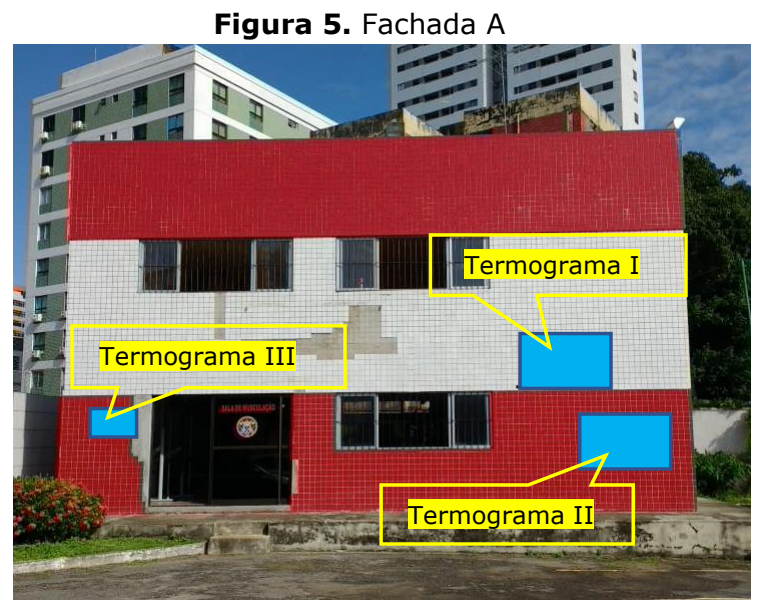

Fonte: Autor

\subsection{Inspeção}

Através de análise visual foram verificadas algumas manifestações patológicas como falha no rejuntamento, eflorescência e descolamento (Figuras 6, 7,e 8).

Após inspeção visual, foi realizada análise termográfica com o uso da câmera termográfica FLIR E-60.
Figura 6. Falha no rejuntamento

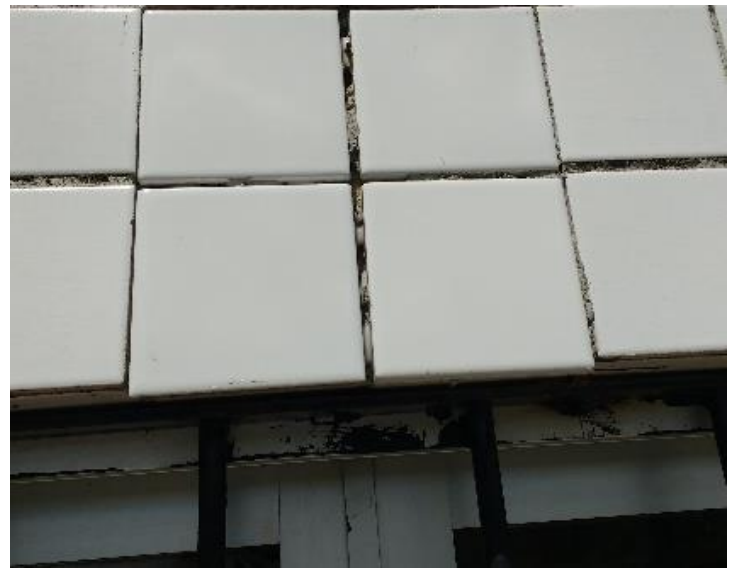

Fonte: Autor

Figura 7. Eflorescência

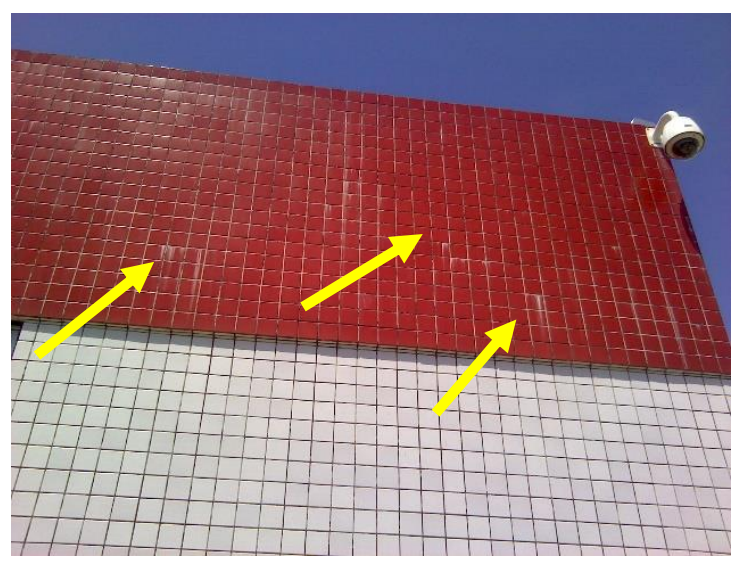

Fonte: Autor

Figura 8. Descolamento de cerâmica em fachada

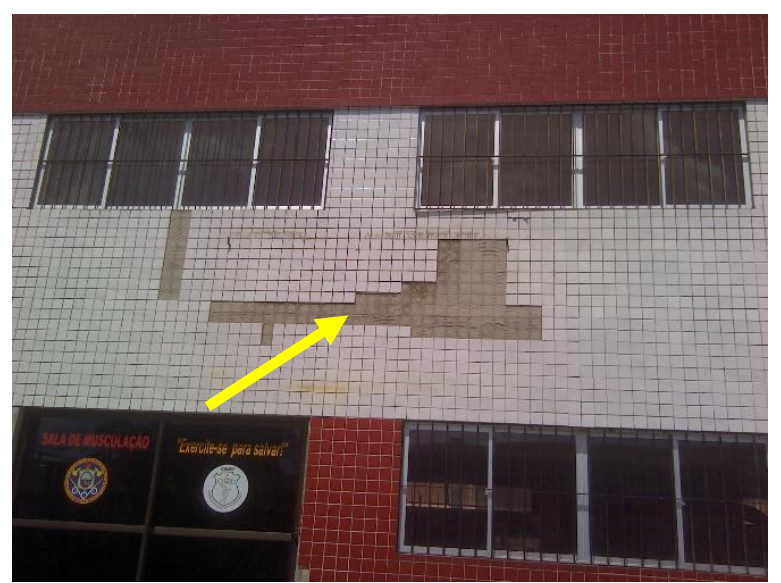

Fonte : Autor 
Para tanto, foi necessário ajustar a câmera para a situação local, medindo e inserindo dados de entrada como: temperatura atmosférica, umidade relativa, emissividade e temperatura refletida. 0 uso de andaimes foi necessário para garantir o correto ângulo de leitura. A distância utilizada variou entre 1 e $10 \mathrm{~m}$.

A emissividade utilizada foi obtida através do uso do método da fita isolante, descrito por Viégas [7]. Este valor foi de 0,65 para a cerâmica branca e 0,70 para a cerâmica vermelha. A umidade relativa e a temperatura atmosférica foram obtidas através do termohigrômetro, tendo como valores $55 \%$ e $30^{\circ} \mathrm{C}$, respectivamente.

Os termogramas foram captados entre às 8 e 10 horas da manhã, horário caracterizado pela maior irradiação solar na fachada, período este, evidenciado por Viégas [7].

\section{Resultados}

Durante ensaio termográfico, foram identificadas três áreas com variação de temperatura, gerando os termogramas I, II e III (Figura 5).

A Figura 9 representa o termograma I, captado na área da cerâmica branca da fachada $A$. No lado direito da figura verifica-se a barra policromática indicando a variação de temperatura, bem como a temperatura máxima e a temperatura mínima obtidas, $43,4^{\circ} \mathrm{C}$ e $33,7^{\circ} \mathrm{C}$, respectivamente. $\mathrm{Na}$ escala policromática a cor mais escura representa pontos mais frios e a cor mais clara representa pontos mais aquecidos da superfície.

Após análise, verificou-se uma grande área da cerâmica com diferença de temperatura de aproximadamente $10^{\circ} \mathrm{C}$, indicando possibilidade de existência de manifestações patológicas.

Seguindo a predisposição da fachada para a manifestação de descolamento cerâmico, realizou-se ensaio de percussão. No ensaio de percussão aplicaram-se impactos leves com martelo de borracha, para verificar a ocorrência de sons cavos ("ocos").

Para a área em estudo foi confirmado som cavo caracterizando a presença de descolamento do revestimento cerâmico.

Neste caso, a técnica da termografia infravermelha mostrou-se eficiente considerando que a fachada apresenta-se visualmente inalterada na área de estudo.
Figura 9. Termograma I
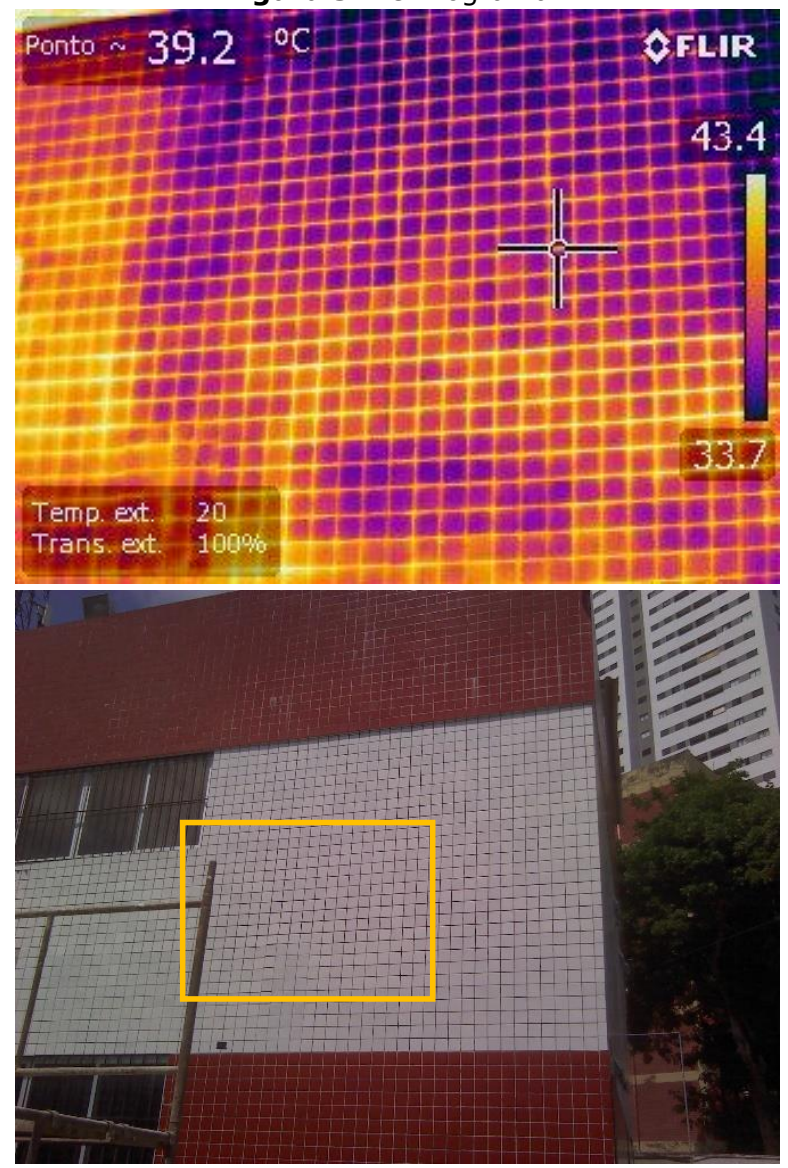

Fonte: Autor

A Figura 10 representa o termograma II, captado na área da cerâmica vermelha da fachada A. A barra policromática indica uma variação de temperatura de $55,1^{\circ} \mathrm{C}$ a $47,2^{\circ} \mathrm{C}$.

Após análise, verificou-se uma área da cerâmica com diferença de temperatura de aproximadamente $8^{\circ} \mathrm{C}$, indicando possibilidade de existência de manifestações patológicas.

Percebe-se também o aumento da temperatura quando comparado à cerâmica branca, fenômeno este já evidenciado por Viégas [7], afirmando que as cores escuras de cerâmica influenciam mais na elevação da temperatura superficial das fachadas, enquanto as cores claras conferem um maior conforto térmico no interior da edificação.

Novamente, após teste de percussão, constatouse som cavo na área de estudo, indicando descolamento da cerâmica. 
Figura 10. Termograma II

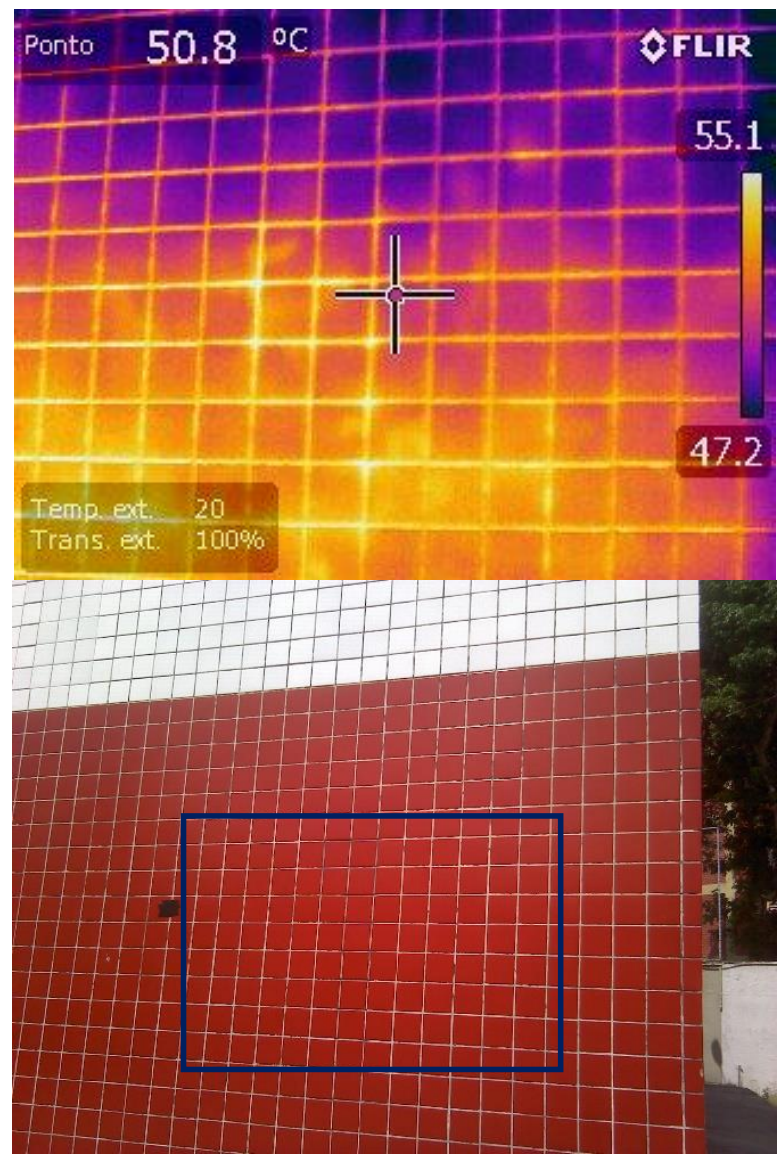

Fonte: Autor

A Figura 11 representa o termograma III, captado em área de transição de cerâmica vermelha e argamassa colante da fachada $A$, onde o descolamento de cerâmica já era evidenciado. A barra policromática indica uma variação de temperatura entre $56,2^{\circ} \mathrm{C}$ a $41,5^{\circ} \mathrm{C}$.

Pela escala policromática, percebe-se que a temperatura na área sem o revestimento cerâmico aproxima-se da temperatura da área com revestimento, indicando a possibilidade de infiltração de ar entre a argamassa colante e a cerâmica. Para que ocorra a infiltração de ar entre estes dois materiais, a cerâmica deve apresentarse descolada da argamassa, justificando a semelhança de temperaturas.

Mais uma vez o teste de percussão indicou som cavo, confirmando o descolamento da cerâmica.

Verificou-se a potencialidade do uso da técnica da termografia infravermelha como ferramenta auxiliar na inspeção de fachadas.
Figura 11. Termograma III

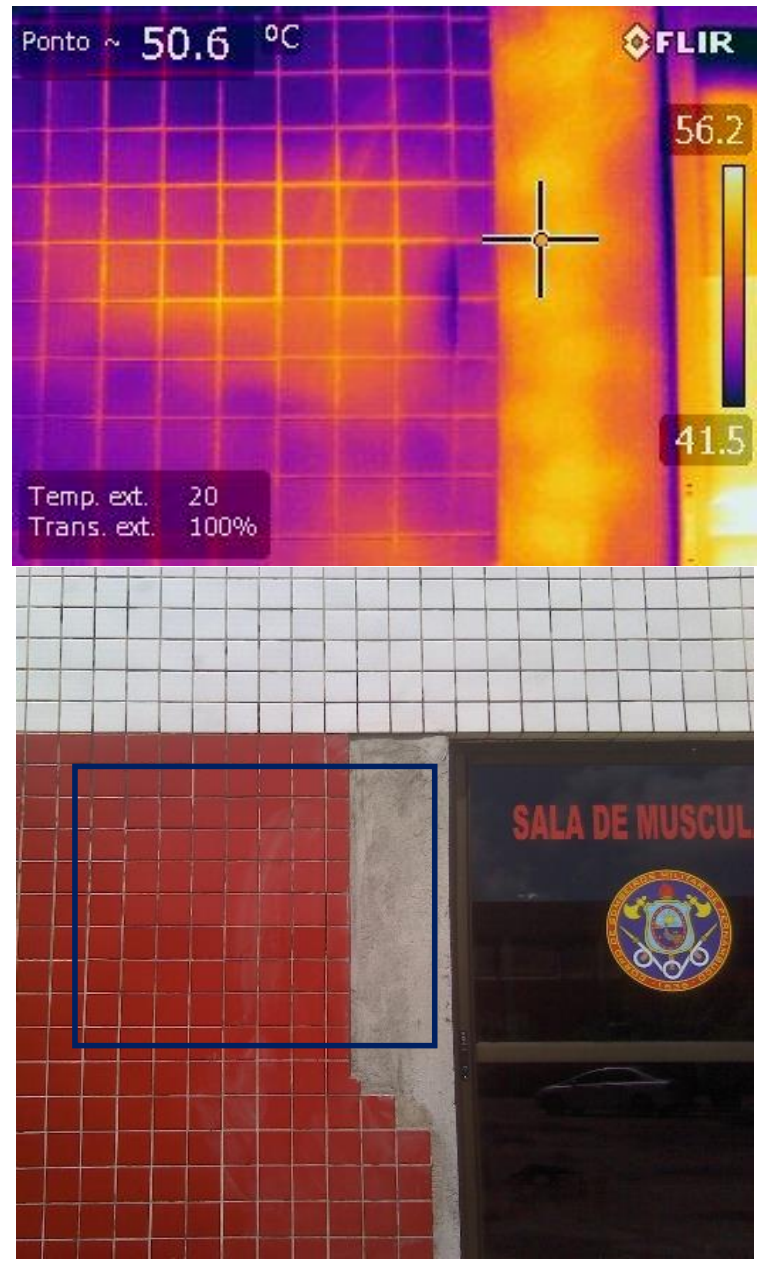

Fonte: Autor

\section{Conclusão}

A vida útil de uma edificação depende não só de um uso adequado. Em todas as fases, desde a concepção do projeto até a execução da obra e as manutenções ao longo do tempo são fatores que influenciam diretamente na durabilidade da construção.

Um projeto mal planejado, que não identifica possíveis agentes agressores à estrutura do prédio, fará com que o empreendimento tenha sua vida útil reduzida. O mesmo acontece quando é executado de maneira inadequada ou quando se utiliza materiais não conformes.

No âmbito da manutenção predial, a termografia infravermelha é uma tecnologia de grande utilidade, permitindo analisar manifestações patológicas existentes ainda na fase embrionária, evitando custos agravados de manutenção. 
Através da termografia infravermelha foi possível notar áreas do revestimento com variação de temperatura, indicando possibilidade de manifestações patológicas, apesar de visualmente a fachada se apresentar inalterada, sendo o descolamento cerâmico confirmado pelo ensaio de percussão. Verificou-se também que a cor dos materiais cerâmicos influencia no desempenho térmico da fachada, constituindo boa prática a correta especificação das cores destes materiais ainda na fase de projeto, baseando-se em considerações técnicas e não apenas estéticas.

\section{Referências}

[1] REVISTA EXAME, Brasil é o segundo maior produtor mundial no setor de revestimentos, disponível em: https://exame.abril.com.br/negocios/dino/ brasil-e-o-segundo-maior-produtor-mundialno-setor-de-revestimentos-shtml/ acesso em 16 de maio de 2018.

[2] BAUER, FALCÃO L.A., Materiais de Construção, Volume 2, 5a edição, 2011.

[3] MATIAS,G.A.;PÓVOAS, Y. V.Estudo de métodos construtivos e materiais aplicados no revestimento cerâmico em fachadas de edificações. 2009. Trabalho de Conclusão de Curso (Graduação em Engenharia Civil) Universidade de Pernambuco. 2009.

[4] ASSOCIAÇÃO BRASILEIRA DE NORMAS TÉCNICAS. NBR 13755. Revestimento de paredes externas e fachadas com placas cerâmicas e com utilização de argamassa colante, Rio de Janeiro, 1997.

[5] MENDONÇA, L.V..Termografia por Infravermelhos: Inspeção de Betão. Revista Engenharia \& Vida, Lisboa, v1, n.16, p.5357,2005 .

[6] CORTIZO,E.C.; BARBOSA, M.P.; SOUZA, L.A.C., Estado da arte da termografia. Fórum Patrimonio: Ambiente Construído e Patrimônio Sustentável, Belo Horizonte, v. 2, n.2, p. 158-193, 2008.

[7] VIÉGAS, D.J.A. Utilização da termografia infravermelha em fachadas para cerificação de descolamento de revestimento. 2015. Dissertação (Mestrado - Construção Civil) Universidade de Pernambuco, Escola Politécnica, Programa de Pós-Graduação em Engenharia Civil, 2015.

[8] SILVA, A.J.; VIÉGAS, D.J.A.; PÓVOAS, Y.V., O Uso da Termofrafia Infravermelha para detecção de Manifestações Patológicas. In: Encontro Nacional de Tecnologia do Ambiente Construído,15. Anais. São Paulo, 2016. 